\title{
Adult Infiltrating Astrocytic Tumor
}

National Cancer Institute

\section{Source}

National Cancer Institute. Adult Infiltrating Astrocytic Tumor. NCI Thesaurus. Code C8289.

An infiltrating astrocytic tumor of the brain occurring in adults. 